\title{
EXISTE O BRASIL? DESAFIOS DE UMA BIOGRAFIA DA NAÇÃO
}

\author{
Does Brazil exist? Challenges \\ of a biography of the nation
}

JOÃO MARCELO EHLERT MAIA

Brasil: uma biografia

Lilia Schwarcz e Heloisa Starling

São Paulo: Companhia das Letras, 2015.

http://dx.doi.org/10.1590/S0103-21862015000200011

João Marcelo Ehlert Maia é mestre (2001) e doutor (2006) em Sociologia pela Sociedade Brasileira de Instrução (SBI/ IUPERJ), e professor adjunto do CPDOC/FGV-RJ (joao.maia@fgv.br).

Resenha recebida em 26 de outubro e aprovada para publicação em 5 de novembro de 2015. 


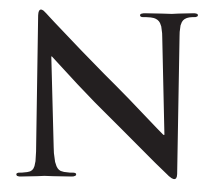

unca foi fácil contar a História do Brasil. Afinal, esse país vasto, desigual e permeado de trocas culturais violentas e criativas sempre se mostrou insubmisso aos seus melhores intérpretes. Mas, em um momento no qual a intensa especialização universitária combina-se a um processo de democratização política e social que pluralizou a ideia clássica de Nação, a tarefa tornou-se ainda mais complexa. Apenas por esse motivo já seria importante saudar o lançamento de um livro como Brasil: uma biografia, escrito em conjunto por Lilia Schwarcz e Heloisa Starling. 0 livro, porém, também é muito bom, o que justifica a ingrata missão de resenhar em no máximo 8 mil caracteres (com espaços!) um livro cujo objeto é apenas o país.

Como se sabe, existe um mercado para livros de História não acadêmicos no Brasil, mas ele tem sido ocupado, de forma geral, por obras escritas por jornalistas ou comentaristas políticos, com algumas exceções recentes (Aarão Reis, 2014). Schwarcz e Starling são não apenas duas pesquisadoras de ponta em suas respectivas áreas, mas também intelectuais preocupadas com a dimensão pública do conhecimento. A primeira tem tido papel relevante na editora Companhia das Letras, organizando coleções que procuram apresentar um panorama atualizado e rico das grandes interpretações do Brasil, ao passo que Starling é uma liderança nos projetos sobre história republicana, atuando também na Comissão Nacional da Verdade. Ambas têm suas trajetórias associadas ao GT de Pensamento Social no Brasil da ANPOCS, espaço dos mais tradicionais e criativos da área, que se notabiliza pelo investimento na pesquisa sobre as tradições culturais e intelectuais nacionais. Assim, é natural que tenham pensado esse projeto a partir do entrecruzamento entre experiência acadêmica, liderança intelectual e visibilidade na esfera pública, produzindo como resultado uma obra que se vale da melhor produção acadêmica disponível, apresentada em um texto acessível aos não iniciados e complementado com grande diversidade de fontes primárias (o livro apresenta logo no início a longa lista de arquivos consultados). A aposta foi bem-sucedida, e ainda hoje Brasil: uma biografia figura nas listas dos livros mais vendidos de não ficção.

A obra tem 18 capítulos distribuídos em quase 800 páginas, que cobrem do período da colonização à transição pós-ditadura militar. Há também seções com imagens, sejam elas 
retratos, pinturas, documentos e fotografias, e as autoras mostram habilidade ao mobilizar essa iconografia de forma não simplesmente ilustrativa. Cada capítulo dialoga intensamente com a historiografia acadêmica, que é apresentada no anexo por meio de notas de fim, embora esse diálogo tenha resultados diferentes em cada seção. Assim, os capítulos sobre o século XIX têm como ponto alto a conversa com a História Intelectual e Conceitual, o que permite ao leitor não especializado um conhecimento maior sobre os significados de termos como "pacto", "federação" e "Império". Já o capítulo sobre escravismo bebe significativamente da fonte da História Social da Escravidão, área na qual a historiografia brasileira tem sido extremamente prolífica e competente. Esse capítulo, em especial, tem forte teor analítico, como se as autoras tivessem conscientemente optado por esmiuçar toda a mecânica violenta do racismo à brasileira, fenômeno que muitos ainda insistem em subalternizar no debate público. Já os capítulos sobre o período republicano (do 13 em diante) parecem privilegiar uma abordagem mais próxima da História Política, e é possível que leitores especializados sintam falta de um diálogo com a História Social do Trabalho mais recente, que vem investindo nos cotidianos dos "mundos do trabalho" para além da discussão sobre o trabalhismo consagrada na obra clássica de Angela de Castro Gomes.

A estrutura narrativa reflete a escrita a quatro mãos, e tem oscilações interessantes. Se alguns capítulos têm um tom analítico, próprio da linguagem acadêmica, outros (em especial o capítulo 4, intitulado "É Ouro!" e dedicado à formação do complexo minerador na atual região de Minas Gerais) têm forte sabor narrativo, com a apresentação quase romanesca de personagens reais extraídas das fontes históricas. É possível que alguns leitores mais críticos se incomodem com o desequilíbrio formal, mas penso que a diversidade de formas atende à diversidade de objetivos. Afinal, em um momento em que ainda se discute a sério a existência de racismo no Brasil, é uma tarefa político-pedagógica martelar no leitor desavisado toda a riqueza informativa e interpretativa produzida pela Historiografia.

0 saldo da empreitada é muito positivo. Gostaria, porém, de destacar dois grandes desafios colocados para qualquer biografia do Brasil hoje: o primeiro relaciona-se com a própria ideia de uma biografia nacional, e o segundo diz respeito às tensões entre as chamadas "interpretações do Brasil" e a emergência de novas narrativas sobre o "Brasil" construídas a partir de perspectivas historicamente subalternas.

Sabemos que a sociologia e a historiografia discutem há tempos as armadilhas contidas no método biográfico (Bourdieu, 1996). Afinal, ao pensarmos a história de um indivíduo como uma biografia, arriscamo-nos a construir uma narrativa por demais dotada de sentido e de coerência, apagando o que seriam os acasos e as contingências que modelam as trajetórias. Mais recentemente, vem-se enfatizando a dimensão transnacional de processos que 
se pensava serem facilmente enquadrados num âmbito exclusivamente nacional ou mesmo regional (Subrahmanyam, 1997), o que põe em questão a possibilidade de uma biografia de uma Nação. Aliás, antes que termos como "História Global" virassem moda intelectual, um historiador como Luiz Felipe de Alencastro (2000) já argumentava que é impossível entender o tráfico negreiro moderno sem tomar como unidade analítica o Atlântico Sul, e não o Brasil. Isto é, a escravização de milhares de africanos em terras tidas como brasileiras não poderia ser entendida como decorrência de uma dinâmica histórica nacional, já que os nexos que explicam esse fenômeno articulariam a costa oeste africana a alguns portos e espaços no litoral brasileiro, mas não todo o território que hoje conhecemos por "Brasil". Assim, uma primeira questão interessante seria: como uma biografia nacional pode dialogar com a necessidade de abordarmos a dimensão transnacional de processos e fenômenos que nos construíram?

0 segundo desafio refere-se ao surgimento de novas formas de falar sobre o objeto "Brasil" que questionam o lugar de discurso dos setores letrados e a ideia de identidade que acompanha a formação do Estado-Nação. Essas novas formas podem ser sintetizadas por uma resposta dada pelo antropólogo Eduardo Viveiros de Castro quando confrontado com a clássica pergunta "O Brasil tem jeito?", em edição recente da revista Cult.

O Brasil não existe: o que existe é uma multiplicidade de povos, indígenas e não-indígenas, sob o tacão de uma elite, corrupta, brutal e gananciosa, povos unificados à força por um sistema mediático e policial que finge constituir-se em um Estado-Nação territorial. Uma fantasia sinistra. Um lugar que é o paraíso dos ricos e o inferno dos pobres. Mas entre o paraíso e o inferno, existe a terra. E a terra é dos índios. E aqui todo mundo é índio, exceto quem não é (Viveiros de Castro, 2015).

A frase contém certo tom apocalíptico, mas traduz um sentimento disseminado sobre o possível esgotamento da forma nacional e seus avatares, entre os quais as próprias "interpretações do Brasil", geralmente produtos do olhar de uma camada letrada sobre um Outro desprovido dos meios materiais e simbólicos de representação. Afinal, não se trata de incluir esses grupos na biografia nacional, tarefa brilhantemente feita pelas autoras, mas de inquirir sobre outras possibilidades narrativas construídas à margem das clássicas interpretações do Brasil e pelas mãos e vozes de outros setores.

As autoras, é claro, estão cientes dos dois desafios aqui levantados, e lidam com eles de forma inteligente. Logo na introdução, afirmam explicitamente que "não querem fazer uma história do Brasil, mas fazer do Brasil uma história, dentre outras". Esta afirmativa sagaz é a bússola de todo o projeto. Cientes da democratização da sociedade e da impossibilidade de qualquer narrativa teleológica, Schwarz e Starling reconhecem a contingência de sua narrativa 
e as contradições do objeto "Brasil". Por tabela, essa frase nos convida a pensar com o livro e para além do livro algumas questões difíceis, mas cruciais, entre as quais eu destacaria duas: se o livro faz do Brasil uma história, como essa história específica, produzida no seio da melhor pesquisa acadêmica nacional, pode se relacionar com outras histórias? Em que medida essas outras histórias ainda encontram um terreno comum com as "intepretações do Brasil" das quais o livro das autoras é claro herdeiro?

Na resposta a essas perguntas, reside um desafio que não é apenas intelectual, mas profundamente político. Afinal, trata-se de encontrar um novo terreno comum em meio aos fragmentos do que é hoje a ideia de Brasil, sacudida por uma maré democratizante de longa duração que felizmente não pode mais ser represada. Brasil: uma biografia será um incontornável livro de viagem nessa busca.

\section{REFERÊNCIAS BIBLIOGRÁFICAS}

AARÃO REIS, Daniel. Luís Carlos Prestes: um revolucionário entre dois mundos. São Paulo: Companhia das Letras, 2014.

ALENCASTRO, Luís Felipe. O trato dos viventes: a formação do Brasil no Atlântico Sul. São Paulo: Companhia das Letras, 2000.

BOURDIEU, Pierre. A ilusão biográfica. In: FERREIRA, Marieta de Morais (org). Usos e abusos da História Oral. Rio de Janeiro: FGV, 1996.

SUBRAHMANYAM, Sanjay. Connected histories: notes towards a reconfiguration of early modern Eurasia. Modern Asia Studies. 31(3): 735-762. 1997.

VIVEIROS DE CASTRO, Eduardo. Eduardo Viveiros de Castro, fotógrafo. Disponível em http://revistacult.uol.com. br/home/2015/07/entrevista-eduardo-viveiros-de-castro-fotografo/. Acessado em 21 de outubro de 2015. 